Rev. Saúde pübl., S. Paulo

$6: 103-5,1972$.

\title{
NOTA SOBRE UM FOCO DE LEISHMANIOSE TEGUMENTAR NA REGIÃO NORDESTE DO ESTADO DE SÃO PAULO, BRASIL *
}

\section{RSPSP-122}

Forattini, O. P. et al. - Nota sobre um foco de Leishmaniose tegumentar na região Nordeste do Estado de São Paulo, Brasil. Rev. Saúde públ., S. Paulo, 6: 103-5, 1972.

Resumo: Relata-se o encontro de um foco de leishmaniose tegumentar no interior do Estado de São Paulo, Brasil. $O$ achado foi levado a efeito em área da regiäo do nordeste, onde a doença não mais foi assinalada, desde 1939. A persistência local de gleba com floresta primitiva faz supor a existência de focos enzooticos naturais.

UNITERMOS: Leishmaniose tegumentar*; Enzootia*; Focos naturais*.

E conceito geral que a leishmaniose tegumentar, antigamente com apreciável prevalência no Estado de São Paulo, Brasil, encontra-se, na atualidade, praticamente desaparecida dessa região (PEssôA 1, 1967). Atribui-se isso às intensas modificaçōes do ambiente motivadas pela ação do homem, em suas atividades agrícola e pastoril. Em vista disso, o encontro de foco ativo dessa moléstia não podia deixar de despertar interesse. E o que se pretende noticiar nesta breve nota.

\author{
Oswaldo Paulo FORATTINI ** \\ Ernesto X. RABELLO * * \\ Dino B. G. PATTOLI ** \\ Octávio Alves FERREIRA * *
}

No decurso de investigações sobre fauna flebotomínica, fomos levados a realizar observações na Fazenda Jataí, onde funciona a Estação Experimental de Luis Antonio, da Secretaria da Agricultura. Essa localidade situa-se no $\mathrm{Mu}$ nicípio do mesmo nome e possui área de floresta primitiva, situada às margens do rio Mogi-Guaçú. Alí deparamos com o primeiro caso humano, na pessoa de um dos guardas residentes. Na outra margem desse curso d'água, já no $\mathrm{Mu}$ nicípio de São Carlos, conseguimos evidenciar mais três doentes, ali residentes e empregados no Pesqueiro Santa Teresinha. A região situa-se na parte nordeste do Estado. Os casos encontrados foram os que seguem, todos do sexo masculino, trabalhadores rurais e surpreendidos no período de agosto a outubro de 1971.

1) OP - 38 anos, residente na localidade há mais de quatro anos, sendo que, há cerca de 30 anos é habitante da região. Ao exame, apresentou uma lesão ulcerosa na face anterior da perna esquerda, com aspecto verrugoso e que, na oportunidade, foi referido ter cerca de seis meses de evolução (Figura 1). Apresentava

* Realizado com o auxílio parcial da Fundação de Amparo à Pesquisa do Estado de Săo Paulo (Proc. C. Médicas 70/788).

* Do Departamento de Epidemiologia da Faculdade de Saúde Públíca da USP - Av. Dr. Arnaldo, 715 - Săo Paulo, SP., Brasil.

** Da Diretoria de Combate a Vetores da Superintenđência do Saneamento Ambiental (SUSAM) do Estado de São Paulo - São Paulo, SP., Brasil . 
FORATTINI, O. P. et. al. - Nota sobre um foco de Leishmaniose tegumentar na regiăo Nordeste do Estado de São Paulo, Brasil. Rev. Saúde públ., S. Paulo, 6:103-5, 1972.

ainda lesões no palato mole. A 23.VIII. 1971 foi feita a intradermoreação de Montenegro a qual revelou-se fortemente positiva à leitura de 48 horas.

2) HS - 42 anos, residente no local há cerca de um ano e meio. Teve uma lesão na face dorso-lateral do tórax que regrediu expontaneamente, tendo o paciente se limitado a aplicaçāo tópica de mercúrio-cromo (sic). Referiu evolução de cerca de cinco meses. Ao exame, apresentava área fortemente infiltrada, eritematosa(Figura 2). A 8.XI.1971 foi feita reação intradérmica de Montenegro que se revelou fortemente positiva a leitura de 48 horas. A retirada de material local mediante punção, para exame microscopico e cultura, forneceram resultados negativos.

3) JOP - 43 anos, morador local há mais de oito anos. Ao exame, mostrou extensa lesão ulcerosa com aspecto francamente vegetante, que o paciente referiu datar de aproximadamente cinco meses (Figura 3). A intradermoreação de Montenegro levada a efeito a 8.XI.1971, resultou fortemente positiva, 48 horas após. O exame parasitológico do material obtido por punção revelou-se positivo ao exame microscópico e a cultura, com o isolamento da cepa. Esta recebeu a sigla acima.

4) AC - 43 anos, residente local há mais de oito anos. Mostrou lesão ulcerosa, arredondada, na face interna da cox́a esquerda com cerca de cinco meses de evolução (Figura 4). A reação intradérmica de Montenegro, realizada a 8.XI.1971, foi fortemente positiva à leitura de 48 horas. $O$ exame parasitológico do material obtido por punção revelouse positivo à microscopia.
Verifica-se pois que se trata de quatro doentes que reagiram positivamente à reação intradérmica, dois deles parasitologicamente comprovados. $O$ caso HS é que se mostra um tanto diferente, pois sua evolução nāo coincide com a dos demais.

A localização da área supracitada encontra-se dentro da zona que Pessós \& Pestana 2 (1940), consideraram como de existência de casos esporádicos. Compulsando os dados apresentados por esses autores, verifica-se a ocorrencia de casos no Município de São Carlos, no ano de 1939. A partir de então, não mais foram noticiados em qualquer ponto da região norte-nordeste do Estado de São Paulo.

A persistência de área florestal primitiva na localidade onde os doentes residem faz pensar na existência de enzootia. Esta poderia revelar-se através de casos isolados, traduzindo-se em estado de endemia baixa, ou mesmo mantendose silenciosa por tempo prolongado. Trata-se pois, de achado que enseja a realização de investigaçōes mais detaIhadas.

RSPSP-122

Forattini, O. P. et al. - [A focus of cutaneous leishmaniasis at the northeast region of the São Paulo State, Brasil]. Rev. Saúde públ., S. Paulo, 6: 103-5, 1972.

Sumamrx - A focus of cutaneous leishmaniasis, in the São Paulo State, Brazil is reported. It was found at the northeast region, were the disease have not noticed since 1939. Evidence of natural enzootic foci of the infection is presented by the local persistence of an primitive forest area.

UNTTERMS - Leishmaniasis, cutaneous*; Natural enzootic foci*. 
FORATTINI, O. P. et. al. - Nota sobre um foco de Leishmaniose tegumentar na região Nordeste do Estado de Säo Paulo, Brasil. Rev. Saúde públ., S. Paulo, 6:103-5, 1972.

\section{REFERENCIAS BIBLIOGRAFICAS}

1 - PESSÓA, S. B. - Parasitologia Médica. 7." ed. Rio de Janeiro, Ed. Guanabara, 1967.

2 - PESSOA, S. B. \& PESTANA, B. R. - Sô. bre a disseminação da leishmaniose te- gumentar no Estado de São Paulo. Resultado de um inquérito realizado nos "Centros de Saúde" do interior. Frolha med., 21 : $20-30,1940$.

Recebido para publicação em 25-11-1971.

Aprovado para publicação em 7-1-1972. 
FORATTINI. O. P. et al. - Nota sobre um foco de Leishmaniose tegumentar na região Nordeste do Estado de São Paulo, Brasil. Rev. Saúde públ., S. Paulo, 6:10345, 1972.

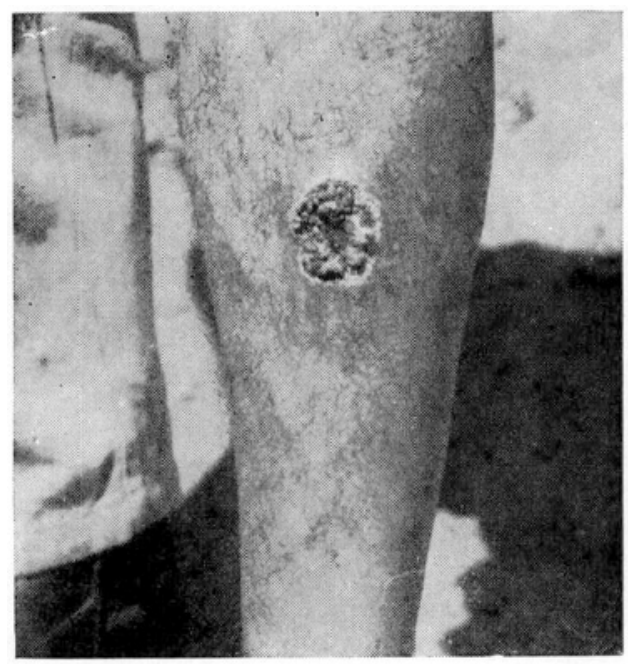

Figura 1 - Caso oP

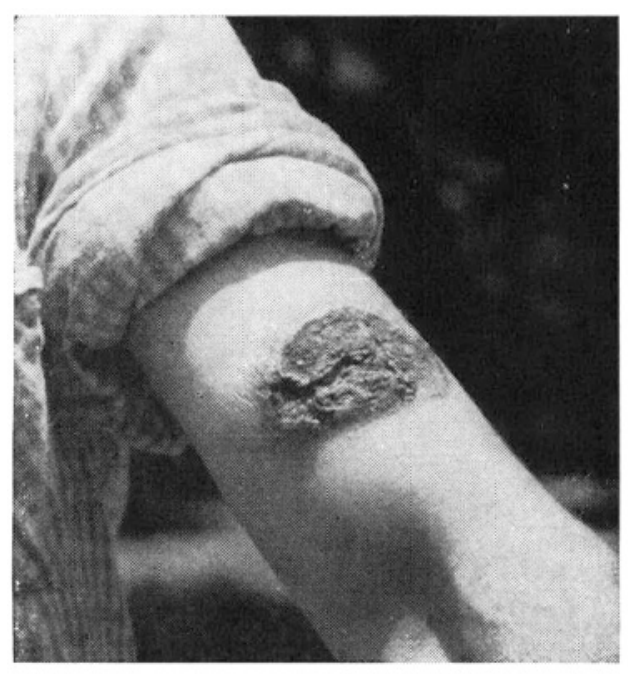

Figura 3 - Caso JOP

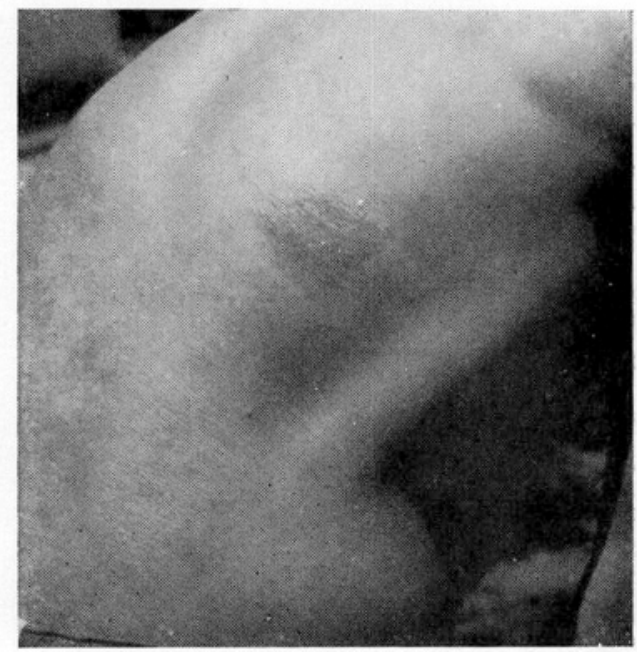

Figura 2 - Caso HS

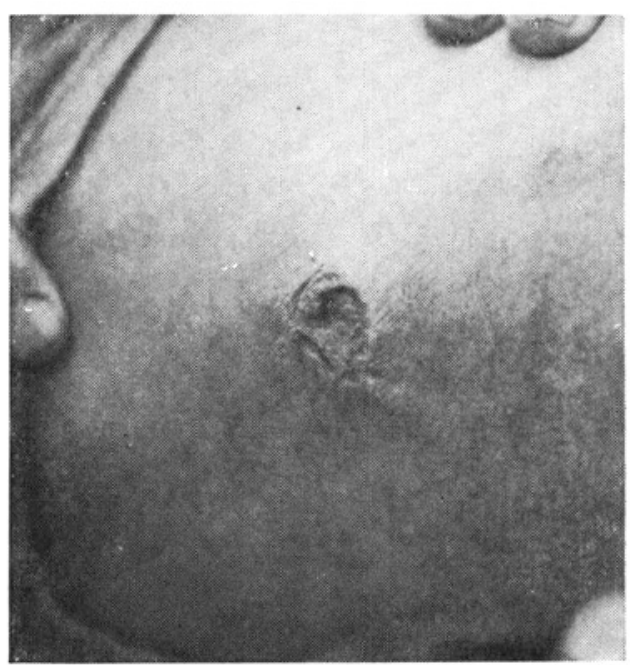

Figura 4 - Caso AC 